Submitted to Materials Science and Engineering A (October 2020); revised (October 2020); second revision (November 2020)

\title{
Evaluating the Paradox of Strength and Ductility in Ultrafine-Grained Oxygen-free Copper Processed by ECAP at Room Temperature
}

\author{
Meshal Y. Alawadhi ${ }^{\mathrm{a}^{*}}$, Shima Sabbaghianrad ${ }^{\mathrm{b}}$, Yi Huang ${ }^{\mathrm{c}, \mathrm{d}^{*}}$, Terence G. Langdon ${ }^{\mathrm{b}, \mathrm{d}}$ \\ aDepartment of Manufacturing Engineering, College of Technological Studies, P.A.A.E.T., \\ P.O. Box 42325, Shuwaikh, 70654, Kuwait \\ ${ }^{\mathrm{b}}$ Departments of Aerospace \& Mechanical Engineering and Materials Science, University of \\ Southern California, Los Angeles, CA 90089-1453, USA \\ ${ }^{\mathrm{c}}$ Department of Design and Engineering, Faculty of Science and Technology, Bournemouth \\ University, Poole, Dorset BH12 5BB, UK \\ ${ }^{\mathrm{d}}$ Materials Research Group, Department of Mechanical Engineering, University of \\ Southampton, Southampton SO17 1BJ, UK
}

\begin{abstract}
Oxygen-free copper of $>99.95 \%$ purity was processed by equal-channel angular pressing at room temperature (RT) for up to 24 passes and then pulled to failure at RT using strain rates from $10^{-4}$ to $10^{-2} \mathrm{~s}^{-1}$. The results show that the microstrain increases with strain at the lower numbers of passes but decreases between 16 and 24 passes. Similar trends were found also for the dislocation density, the Vickers microhardness and the values of the measured yield stresses in tensile testing. X-ray diffraction measurements showed a minor increase in the crystallite size at the high strain imposed by processing through 24 passes. These results demonstrate the occurrence of dynamic recovery at the highest strain. In tensile testing at a strain rate of $10^{-3} \mathrm{~s}^{-1}$ the results gave a yield stress of $\sim 391 \mathrm{MPa}$ and an elongation to failure of $52 \%$ which is consistent with an earlier report using $\mathrm{Cu}$ of much higher purity but not consistent with an earlier report using $\mathrm{Cu}$ of the same purity.
\end{abstract}

Keywords: Copper; Ductility; Equal-channel angular pressing; Strength; Ultrafine grains Corresponding author: Meshal Y. Alawadhi (my.alawadhi@PAAET.EDU.KW), 


\section{Introduction}

For polycrystalline materials, the grain size, $d$, is generally considered the most important microstructural parameter because it has a major influence on both the overall strength and the flow properties. It is now well established that the strength of a material varies with grain size through the Hall-Petch relationship [1,2] which states that the yield stress, $\sigma_{\mathrm{y}}$, is given by the equation

$$
\sigma_{\mathrm{y}}=\sigma_{\mathrm{o}}+k_{\mathrm{y}} d^{-1 / 2}
$$

where $\sigma_{\mathrm{o}}$ is the lattice friction stress and $k_{\mathrm{y}}$ is a constant associated with yielding. It follows from eq. (1) that the strength increases when the grain size is reduced so that small grain sizes are attractive for the production of high-strength materials for use in industrial applications. There are numerous recent reports examining the precise significance of the Hall-Petch relationship [3,4] and, in addition, if the grain size is reduced to less than $\sim 10 \mu \mathrm{m}$ then the material also has a potential for exhibiting superplastic flow properties [5] so that it becomes viable for use in commercial superplastic forming operations [6].

In industrial practice, a refinement in grain size is generally achieved through thermo-mechanical processing but this procedure is limited because it is not capable of producing grain sizes smaller than a few micrometers. An alternative process was proposed in 1988 when an aluminium alloy was produced with a submicrometer grain size of $\sim 0.3 \mu \mathrm{m}$ using a special processing technique based on the application of severe plastic deformation (SPD) without incurring any significant change in the overall dimensions of the workpiece [7]. Subsequently, this type of SPD processing attracted much attention and it is now used widely for the production of metals with submicrometer or nanometer grain sizes [8,9]. Several different SPD processing methods are now available $[10,11]$ but the two main processes are equal-channel angular pressing (ECAP) and high-pressure torsion (HPT) [12]. In processing by ECAP the sample is in the form of a rod or bar and it is pressed through a die constrained 
within a channel that is bent through a sharp angle [13] whereas in processing by HPT the sample is usually in the form of a thin disk and it is placed between massive anvils and subjected to a high applied pressure and concurrent torsional straining [14]. Both of these procedures are effective in producing ultrafine-grained (UFG) materials but HPT has an advantage over ECAP because the grains are generally smaller $[15,16]$ and there are higher fractions of grain boundaries having high angles of misorientation [17].

Although SPD processing is effective in refining the grain size and introducing high strength, experiments show that UFG metals generally exhibit only very limited ductilities or elongations to failure. This very limited ductility has given rise to the so-called paradox of strength and ductility [18] which is best summarized by the maxim that "materials may be strong or ductile, but rarely both at once" $[19,20]$. Nevertheless, in the first comprehensive analysis of strength and ductility, it was shown that there is a potential for achieving "extraordinary combinations of high strength and high ductility" in metals processed by SPD provided the materials are subjected to very high strains [18]. Thus, an analysis of data for a wide range of metals processed by conventional techniques such as rolling, drawing or extrusion showed that all of these materials exhibited combinations of low ductilities or low yield strengths whereas two metals having nanocrystalline structures produced by extensive SPD processing produced both good strength and good ductility. These two metals were very high purity (99.996\%) $\mathrm{Cu}$ processed by ECAP through 16 passes at room temperature (RT) and pure (99.98\%) Ti processed by HPT through 5 revolutions at RT where both SPD processing methods produced grain sizes of $\sim 100 \mathrm{~nm}$ and tensile testing with a strain rate of $10^{-3} \mathrm{~s}^{-1}$ gave elongations to failure of $\sim 51 \%$ and $\sim 43 \%$ for $\mathrm{Cu}$ and $\mathrm{Ti}$, respectively [18].

The general low ductility in materials with small grain sizes is due to their low strain rate sensitivity and low rate of strain hardening where strain hardening is restricted because the small grains provide only a limited capability for dislocation storage so that the dislocations 
move readily through the grains and become absorbed in the grain boundaries $[21,22]$. This means that the elongations are limited for UFG structures even in metals that are inherently ductile when having coarse grain sizes [23].

In attempts to overcome this problem, numerous strategies were developed in order to establish processing procedures that provide good ductility in UFG materials in addition to high strength [24-31]. Following an earlier demonstration that the ductility of Ti processed by HPT may be improved by subjecting the material to a very short-term anneal immediately after SPD processing [32], similar short-term anneals were effectively performed to improve the ductilities of an Al-1\% Mg alloy [33] and pure Ta [34] processed by HPT, Ti processed by ECAP with warm rolling and drawing [35] and Ti processed by ECAP/Conform with drawing [36].

The early demonstration that good strength and ductility may be achieved by SPD processing to high strains was also addressed in some later investigations. Using an $\mathrm{Al}-7 \% \mathrm{Si}$ alloy and processing by HPT for up to 10 turns it was shown that, in agreement with the earlier results on $\mathrm{Cu}$ and $\mathrm{Ti}[18]$, high strength and high ductility were achieved after processing through the highest numbers of HPT revolutions [37]. By contrast, in an investigation of commercial purity (>99.95\%) $\mathrm{Cu}$ processed by ECAP at RT from 1 to 16 passes it was concluded that "no increase in total elongation with an increase in the number of passes could be measured" and when testing with a strain rate of $1.6 \times 10^{-3} \mathrm{~s}^{-1}$ the elongation to failure after 16 passes was recorded as $10.0 \%$ [38]. This result is remarkably different from the earlier report of an elongation of $\sim 51 \%$ [18] despite processing by ECAP to 16 passes at the same temperature in both experiments using identical dies with an internal channel angle of $90^{\circ}$ and then subsequently testing in tension at an almost identical strain rate. One difference between these two sets of experiments is the initial purities of the samples but no evidence is at present available to suggest any critical effect of purity on the overall ductility. Accordingly, the 
present investigation was initiated both to specifically address this apparent dichotomy and, in addition, to provide comprehensive information on the nature of flow in polycrystalline $\mathrm{Cu}$ processed by ECAP to a range of different strains.

\section{Experimental material and procedures}

The experiments were conducted using oxygen-free (OF) copper having a commercial purity of $>99.95 \%$. The material was initially annealed for one hour in a vacuum tube furnace at a temperature of $600^{\circ} \mathrm{C}$ before processing by ECAP. Copper billets having lengths of 65 $\mathrm{mm}$ and diameters of $10 \mathrm{~mm}$ were processed by ECAP at room temperature using processing route $\mathrm{B}_{\mathrm{C}}$ in which the sample is rotated about the longitudinal axis by $90^{\circ}$ in the same direction between each pass [39]. The billets were pressed through a solid die constrained within a channel bent through an internal angle of $\Phi=110^{\circ}$ and with an outer curvature of $\psi=20^{\circ}$ where these angles introduce a strain of $\sim 0.76$ on each separate pass [40]. To evaluate the effect of the imposed strain, samples were pressed separately through 2, 4, 6, 8, 16, 20 and 24 passes thereby giving a maximum strain after 24 passes of $\sim 18.2$. A maximum of 24 passes was selected because the total strain is then very similar to the total strain of $\sim 18.4$ imposed by 16 passes in the earlier experiments using an ECAP die with a channel angle of $90^{\circ}[18,38]$. In addition, it was impossible to impose a higher strain because there was evidence for cracking when the billets were pressed beyond 24 passes.

The microstructures were evaluated before and after ECAP using an analytical field emission scanning electron microscope (SEM), JEOL JSM-7001 F, at an operating voltage of $15 \mathrm{kV}$. The microstructural images were recorded using electron backscatter diffraction (EBSD) and orientation-imaging microscopy (OIM) with OIM ${ }^{\mathrm{TM}}$ software and a TSL orientation-imaging system was used for data collection. The EBSD patterns were collected at a working distance of $15 \mathrm{~mm}$ with a sample tilt of $70^{\circ}$ and the OIM images were plotted using a step size of $0.05 \mu \mathrm{m}$. High-angle grain boundaries (HAGBs) were classified as those with 
misorientations between neighbouring measuring points of $>15^{\circ}$ whereas misorientation differences of $2^{\circ}$ to $15^{\circ}$ were classified as low-angle grain boundaries (LAGBs).

X-ray diffraction (XRD scans were performed using a Bruker D2 Phaser X-ray diffractometer equipped with a copper target using $\mathrm{Cu} \mathrm{K \alpha}(\lambda=0.15406 \mathrm{~nm})$ radiation to analyse the surfaces. The XRD patterns were recorded by performing scans covering an angular $2 \theta$ range from $30^{\circ}$ to $100^{\circ}$ and Materials Analysis Using Dffraction (MAUD) software [41] was used to perform the profile fitting. The crystallite sizes and microstrains were estimated using the Rietveld method [41] and the dislocation density, $\rho$, was calculated using the microstructural data obtained from the MAUD software with the equation $[43,44]$ :

$\rho=\frac{2 \sqrt{3}\left\langle\varepsilon^{2}\right\rangle^{1 / 2}}{D_{c} b}$

where $\left\langle\varepsilon^{2}\right\rangle^{1 / 2}$ is the lattice microstrain, $D_{c}$ is the average crystallite size and $b$ is the Burgers vector. Since copper is a face-centered cubic (f.c.c.) metal that preferentially slips on the $\{111\}$ plane in the $\langle 110\rangle$ direction, the Burgers vector is $\frac{a}{\sqrt{2}}$ where $a$ is the lattice parameter.

Measurements of the Vickers microhardness were taken using a Future-Tech microhardness tester, FM-300, by applying an indentation load of 100 gf and maintaining during a dwell time of $15 \mathrm{~s}$. In addition, tensile tests were conducted at RT using a Zwick tensile testing machine and with the specimens pulled to failure at constant rates of cross-head displacement using initial strain rates of $1.0 \times 10^{-2}, 1.0 \times 10^{-3}$ and $1.0 \times 10^{-4} \mathrm{~s}^{-1}$. To ensure reproducibility in measurements of the elongations to failure, four specimens were cut from each ECAP billet with gauge lengths of $4 \mathrm{~mm}$ and cross-sections of $3.0 \times 2.0 \mathrm{~mm}^{2}$.

\section{Experimental results}

\subsection{Microstructural evolution}

The microstructures of the initial annealed and ECAP-processed copper samples were examined by EBSD as shown in the OIM images in Fig. 1 where the colours correspond to the 
different grain orientations as represented by the unit triangle on the left, PD is the pressing direction and the OIM was conducted on the longitudinal planes of the processed billets. The distributions of the grain boundary misorientation angles are shown for these samples in Fig. 2. Average grain sizes were determined for each sample from the average spacing between the HAGBs.

Inspection of Fig. 1(a) shows that the initial annealed sample contains relatively large grains with an average size of $\sim 24 \mu \mathrm{m}$ and from Fig. 2(a) there are $\sim 88 \%$ HAGBs, $\sim 12 \%$ LAGBs and the distribution shows there is a high fraction (>17\%) of twin boundaries. After 2 passes in Figs 1(b) and 2(b), the microstructure contains reasonably large and elongated grains with an average size of $\sim 14 \mu \mathrm{m}$ and with $\sim 64 \%$ HAGBs and $\sim 36 \%$ LAGBs. Increasing to 4 passes, the microstructure contained a mixture of small grains and elongated grains, the average grain size was reduced to $\sim 4.4 \mu \mathrm{m}$ and the percentage of HAGBs increased to $\sim 74 \%$. After 8 passes in Fig. 1(d) and 2(d), there were both equiaxed and elongated grains with an average size of $\sim 2.9 \mu \mathrm{m}$ and the fraction of HAGBs further increased to $\sim 76 \%$. With increasing strain to 16 passes in Fig. 1(e), the microstructure became reasonably equiaxed with an average size of $\sim 1.3 \mu \mathrm{m}$ and $\sim 80 \%$ HAGBs in Fig. 2(e). Finally, after the maximum of 24 ECAP passes in Fig. 1(f) the microstructure was homogenous with well-defined boundaries, there was a uniform array of equiaxed grains of average size $\sim 0.6 \mu \mathrm{m}$ and with $\sim 88 \%$ HAGBs in Fig. 2(f). It is concluded from these results that a homogeneous UFG microstructure may be achieved in oxygen-free copper by processing to high strains and it is noted that the average grain size decreases and the fraction of HAGBs increases with increasing numbers of ECAP passes.

Fig. 3(a) shows the estimated crystallite sizes and microstrain values obtained from analyses of the X-ray diffraction data with the very small error bars calculated using the MAUD software. There was an initial decrease in the crystallite size with increasing strain from a value of $\sim 194 \mathrm{~nm}$ after 2 passes to $\sim 111 \mathrm{~nm}$ after 16 passes and then an increase to $\sim 134 \mathrm{~nm}$ 
after 24 passes. It is readily apparent that the crystallite sizes determined by XRD are significantly smaller than the average grain sizes measured by EBSD. This difference is wellestablished in materials science [45,46] and it arises because XRD measures the mean size of the domains which scatter X-rays coherently whereas EBSD measures a grain size based on the average separation between the HAGBs [47]. The microstrain characterizes the concentration of crystallite defects in the copper samples and it is evident from Fig. 3(a) that the microstrain increases with increasing strain up to 16 passes but then decreases to 24 passes. The dislocation density was calculated from the X-ray data using eq. (2) and the results are given in Fig. 3(b). It is readily apparent that the dislocation density and microstrain display similar variations with the numbers of ECAP passes. Thus, the dislocation density was $\sim 3.9 \times$ $10^{12} \mathrm{~m}^{-2}$ in the initial annealed condition but increased to a maximum of $\sim 4.0 \times 10^{14} \mathrm{~m}^{-2}$ after 16 passes and then decreased to $\sim 2.2 \times 10^{14} \mathrm{~m}^{-2}$ after 24 passes. This decrease after higher numbers of passes provides evidence for the occurrence of some dynamic recovery after 16 passes of ECAP and this is consistent with data reported for pure $\mathrm{Cu}$ processed by simple shear extrusion (SSE) through 12 passes where the dislocation density increased from 1 to 8 passes and then decreased [48].

The evolution in microhardness with numbers of ECAP passes is shown in Fig. 4 where each value is the average recorded on the longitudinal planes of the ECAP billets for each processing condition. Thus, the hardness was initially $\mathrm{Hv} \approx 41$ in the annealed condition but increased abruptly to $\mathrm{Hv} \approx 105$ after 2 passes, gradually further increased to $\mathrm{Hv} \approx 120$ after 16 passes and then decreased to $\mathrm{Hv} \approx 112$ after 24 passes. This variation in microhardness reasonably matches the variation in the dislocation density in Fig. 3(b) with a peak value after 16 passes and then a decrease up to 24 passes. These microhardness values are also consistent with the occurrence of dynamic recovery when processing beyond 16 passes. 


\subsection{The strength and ductility behaviour after ECAP}

Plots of the engineering stress against the engineering strain are shown in Fig. 5 for tests conducted at RT with initial strain rates of $1.0 \times 10^{-2}, 1.0 \times 10^{-3}$ and $1.0 \times 10^{-4} \mathrm{~s}^{-1}$ where the lower dashed lines denote the initial annealed condition. The values of the yield stresses (YS) were taken as the $0.2 \%$ strain offsets and these values and the associated elongations to failure (EL) are summarized in Table 1. It is apparent from Table 1 that the initial annealed copper exhibits a low yield stress of $\sim 90 \mathrm{MPa}$ when testing at $1.0 \times 10^{-2} \mathrm{~s}^{-1}$ and the elongation to failure was then $\sim 95 \%$ which is typical of coarse-grained metals. The strength increased significantly to $\sim 371 \mathrm{MPa}$ after 2 passes but the elongation then decreased to $\sim 38 \%$. Thereafter, the YS reached a maximum of $\sim 430 \mathrm{MPa}$ after 16 passes and then decreased to $\sim 410 \mathrm{MPa}$ after 24 passes. Throughout these tests the measured elongations to failure increased slightly with increasing numbers of passes, ultimately reaching $\sim 43 \%$ after 24 passes. The same general trends of increasing YS to 16 passes and then a decrease in YS at 24 passes, together with an increasing elongation to failure with increasing strain up to 24 passes, were recorded also at the other two testing strain rates.

\subsection{Measures of the uniform elongations after ECAP}

The uniform elongation is defined formally as the elongation occurring at the point of maximum load, immediately before the onset of necking in tensile testing. The uniform elongations were investigated in this investigation and Table 2 provides a comprehensive summary of the ultimate tensile stress (UTS) and uniform elongation (UEL) for the oxygenfree $\mathrm{Cu}$ specimens processed by ECAP over a range of strain rates for various numbers of passes. Thus, the UTS increased gradually with increasing strain at all strain rates from 2 to 16 passes and then decreased slightly at 24 passes. By contrast, the uniform elongation increased with increasing strain from 2 to 24 passes at all three strain rates. These results show 
that the variation of the UTS is similar to the YS and the variation of the uniform elongation is similar to the elongation to failure at all testing strain rates.

\subsection{Strain rate sensitivity and the work-hardening rate}

The strain rate sensitivity, $m$, is defined as

$$
m=\left(\frac{\partial \ln \sigma}{\partial \ln \dot{\varepsilon}}\right)_{\varepsilon}
$$

where $\sigma$ is the true stress, $\dot{\varepsilon}$ is the strain rate and $\varepsilon$ is the true strain.

The values of the strain rate sensitivity were calculated for the copper samples tested at RT at strain rates from $10^{-2}$ to $10^{-4} \mathrm{~s}^{-1}$ and the results are shown in Fig. 6 where the lower broken line denotes the initial annealed sample. It is readily apparent that the values of $m$ are generally higher for the ECAP samples than for the annealed samples but these values are not sufficient to delay the onset of necking. In addition, the values of $m$ increase at slower strain rates reaching maximum values of $\sim 0.021$ and $\sim 0.028$ after 16 and 24 passes, respectively.

In order to evaluate the onset of localized deformation during tensile testing, the workhardening rate, $\Theta$, was calculated from the relationship [49]:

$$
\Theta=\left(\frac{\partial \sigma}{\partial \varepsilon}\right)
$$

Using eq. (4), Fig. 7 shows the calculated work-hardening rate as a function of true strain where it is apparent that the sample processed through 24 passes has a higher workhardening rate at any selected strain by comparison with samples processed through smaller numbers of passes. This result demonstrates that there is a greater uniformity in elongation with increasing numbers of passes.

\section{Discussion}

\subsection{The Hall-Petch relationship}

It is well-established that reducing the grain size increases the strength of polycrystalline materials as described by the Hall-Petch relationship shown in eq. (1) $[1,2]$. 
However, softening behaviour may occur when the grains are reduced below a certain critical size so that the deformation mechanism changes from a dislocation activity to a grain boundary related process [50-52]. In order to obtain a better understanding of the Hall-Petch relationship for oxygen-free copper, the yield stress was plotted as a function of the inverse of the square root of the average grain size as shown in Fig. 8. This conventional Hall-Petch plot is clearly not linear over the total range of grain sizes used in this investigation but instead it is consistent with eq. (1) over the range of $d^{-1 / 2}<880 \mathrm{~m}^{-1 / 2}$ but there is a decrease at smaller grain sizes where $d^{-1 / 2}>880 \mathrm{~m}^{-1 / 2}$ thereby giving a negative value for the yielding constant $k_{\mathrm{y}}$ in eq. (1). These results show a transition from strengthening to softening and the occurrence of an inverse HallPetch effect at grain sizes smaller than $\sim 1 \mu \mathrm{m}$ where this value is very high compared with the transition grain size of $\sim 12 \mathrm{~nm}$ estimated for copper from molecular dynamic simulations [53$55]$.

\subsection{Strengthening mechanisms for the ECAP process}

The present experiments provide clear evidence for a simultaneous increase in strength and ductility of oxygen-free copper after processing by ECAP for up to 24 passes at RT as documented in Fig. 5. The increase in elongation is associated with a drop in strength occurring at a certain strain level in the ECAP processing which corresponds to the occurrence of softening. This is contrary to several earlier SPD studies on copper where there was an increase in strength with increasing strain but ultimately the values appeared to reach a reasonable steady-state plateau without the occurrence of any softening: similar behaviour was reported from investigations using either ECAP [56-59] or HPT [58,60-65]. Nevertheless, the strain softening observed in this study at the highest level of strain, corresponding to the maximum of 24 passes, is consistent with the reduction in dislocation density after large numbers of passes as shown in Fig. 3(b) and the corresponding increase in the crystallite size as shown in Fig. 3(a). The softening is also consistent with results for high purity $\mathrm{Cu}$ processed by ECAP 
at RT using a die with a channel angle of $90^{\circ}$ where there was a peak in strength after 8 passes [66].

Two strengthening mechanisms contribute to the strength of oxygen-free $\mathrm{Cu}$ : grain boundary strengthening, $\sigma_{\mathrm{GB}}$, and dislocation strengthening, $\sigma_{\mathrm{dis}}$. Thus, the total strength is a combination of these strengthening mechanisms with the assumption that each mechanism operates independently so that [67-71]

$$
\sigma=\sigma_{0}+\sigma_{\mathrm{GB}}+\sigma_{\mathrm{dis}}
$$

Grain boundary strengthening arises from the Hall-Petch relationship as given in eq. (1) whereas dislocation strengthening is described by the Taylor equation as [72]

$$
\sigma_{\text {dis }}=\alpha M G b \rho^{1 / 2}
$$

where $\alpha$ is a numerical factor depending on the arrangement of dislocations, $M$ is the Taylor factor having value of $\sim 3$ for uniaxial tensile deformation in the full-constraint model [73-75] and $G$ is the shear modulus.

In practice, the dislocation density and the yield strength generally show similar evolutions as a function of strain when processing by ECAP [76] and the saturation yield strength is related to the maximum dislocation density through the Taylor equation for a range of metals processed by f.c.c. [77]. The dislocation density increases while the crystallite size decreases with strain during the deformation process [76,78] as shown in Fig. 3 but the strength may be reduced by a lower dislocation density [30]. Combining eqs. (1) and (7), it follows that the yield stress may be expressed as

$$
\sigma=\sigma_{0}+\alpha M G b \rho^{1 / 2}+k_{\mathrm{y}} d^{-1 / 2}
$$

The estimated yield stress is plotted with respect to the number of passes in Fig. 9 and it is apparent that the overall trend has similarities to the values of the Vickers microhardness in Fig. 4 so that both grain boundary strengthening and dislocation strengthening contribute to the overall strengthening of the oxygen-free copper during ECAP. Thus, the observed 
softening after 24 passes of ECAP shown in Fig. 9 is related both to the decrease in the dislocation density and the concurrent increase in the crystallite size.

\subsection{Examining the paradox of strength and ductility}

The present investigation was conducted to provide a comprehensive evaluation of the mechanical properties of pure oxygen-free $\mathrm{Cu}$ processed by ECAP with the overall objective of making a direct comparison with earlier data by Valiev et al. [18] and Dalla Torre et al. [38] where there was a very clear discrepancy between the elongations to failure recorded after processing to the same high strain.

Basically, the results from the present investigation are generally consistent with other data but they also reveal additional features that were not reported in earlier experiments. For example, the results show that the microstrain increases with strain at lower numbers of passes but decreases between 16 and 24 passes as in Fig. 3(a). This trend is similar to the dislocation density in Fig. 3(b), the measurements of the Vickers microhardness in Fig. 4 and the values of the yield stress documented in Table 1. There is also a minor increase in the crystallite size at the highest strain as determined from XRD and shown in Fig. 3(a). All of these results are consistent with the occurrence of dynamic recovery at the highest strain imposed by the ECAP processing.

Table 3 provides a direct comparison of the present results with the data reported earlier by Valiev et al. [18] and Dalla Torre et al. [38] where the strain rate sensitivity for the latter investigation was taken from earlier experiments conducted on the same material but using strain rate jump tests in compression [79]. These two earlier experiments showed a marked inconsistency because they both processed pure $\mathrm{Cu}$ by ECAP under similar conditions to the same imposed strain of $\sim 18.4$ and yet Valiev et al. [18] recorded a tensile elongation of $51 \%$ whereas, testing in tension under almost identical conditions, Dalla Torre et al. [38] recorded an elongation of only $10 \%$. The precise experimental conditions are summarized in the top 
two lines of Table 3 and the present results are given in the bottom line. A possible significant difference between the two earlier investigations was the use of $\mathrm{Cu}$ having purities of either $99.996 \%$ [18] or $>99.95 \%$ [38]. The present investigation used a material of $>99.95 \%$ purity which was similar to Dalla Torre et al. [38] and yet the results in this investigation confirmed the earlier data of Valiev et al. [18] conducted using the very high purity material. The present results demonstrate, therefore, that the purity level of $\mathrm{Cu}$ has no significant effect on the measured elongations to failure. An alternative possibility is that the differences in the measured elongations may arise because of the use of tensile samples having different gauge lengths and cross-sectional areas. Further investigation will be required in order to examine this possibility.

The present investigation used a die with a channel angle of $110^{\circ}$ instead of $90^{\circ}$ but the maximum number of passes was adjusted so that all three sets of experiments experienced similar total strains. Thus, the calculated strains were $\sim 18.4$ after 16 passes using a $90^{\circ}$ die $[18,38]$ and $\sim 18.2$ after 24 passes in the present experiments using a $110^{\circ}$ die. This approach is reasonable because earlier experiments showed that it was acceptable to compare results from samples processed in ECAP dies having different channel angles provided the imposed strain was maintained reasonably similar $[80,81]$. The earlier examination of channel angles in ECAP showed also that smaller grain sizes were achieved by imposing a number of reasonably large strains in ECAP rather than by achieving the same strain cumulatively by imposing a larger number of smaller strains [80]. This conclusion is directly consistent with the present results where Valiev et al. [18] used an ECAP die with $\Phi=90^{\circ}$ and reported a grain size of $\sim 400 \mathrm{~nm}$ whereas the present investigation used a die with a channel angle of $\Phi=110^{\circ}$ and obtained a grain size of $\sim 600 \mathrm{~nm}$.

A detailed comparison of the results in Table 3 show that the present data are in excellent agreement with the earlier results of Valiev et al. [18]. Specifically, under the same 
tensile testing conditions the measured values of the yield stress were $\sim 391 \mathrm{MPa}$ in the present experiments and $\sim 400 \mathrm{MPa}$ in the earlier investigation [18] and, for the same tensile testing conditions, the elongations to failure were $52 \%$ in these experiments and $51 \%$ in the investigation by Valiev et al. [18]. There is an apparent difference in the values of $m$ between these two investigations but this difference should be investigated by conducting additional detailed experiments using strain rate jump testing. Nevertheless, it is important to note that recent experiments on the Al-Mg system using HPT processing showed that the value of $m$ increases over at least the range from 20 to 100 turns [82] and therefore a reasonably high value of $m$ may be anticipated after processing by ECAP to a high strain.

The conventional plot of yield stress versus elongation to failure, which was first produced in defining the paradox of strength and ductility, is shown in Fig. 10 [18]. In this diagram, conventional metals generally exhibit either high strength or high ductility so that their datum points lie within the shaded area shown below the line at the lower left of the diagram. In Fig. 10 the numbers against the lines contained in the shaded area for $\mathrm{Al}$ and $\mathrm{Cu}$ denote the strains imposed in rolling and the original plot also included datum points for other materials such as $\mathrm{Co}, \mathrm{Mg}$ and $\mathrm{Ti}$. It was also shown by Valiev et al. [18] that Ti processed by HPT for 10 turns and $\mathrm{Cu}$ processed by ECAP through 16 passes using a die with a channel angle of $\Phi=90^{\circ}$ exhibited the solid square points which lie outside of the conventional shaded area. These two points are labelled nano $\mathrm{Ti}$ and nano $\mathrm{Cu}$ in Fig. 10 and the plot also includes, as shown by the solid circular point, the result for $\mathrm{Cu}$ processed by ECAP to a similar total strain in the present investigation. Thus, the present result is in excellent agreement with the earlier result reported by Valiev et al. [18] for pure $\mathrm{Cu}$.

Finally, it should be noted that the line in Fig. 10 separating conventional materials from the points exhibiting excellent strength and ductility is drawn arbitrarily in the diagram so that the position of the line is not well defined. It has been shown that a similar but more 
realistic diagram may be presented by plotting the normalized yield stress, given by the measured yield stress divided by the yield stress for the as-cast material, $\mathrm{YS} / \mathrm{YS} \mathrm{S}_{\mathrm{as}-\mathrm{cast}}$, against a normalized elongation to failure where the elongation is divided by the value of the elongation to failure for the as-cast condition, $\varepsilon_{\text {fail }} / \varepsilon_{\text {fail-as-cast }}[37,83]$. Plotting in this format, it follows that the line where $\mathrm{YS} / \mathrm{YS}_{\mathrm{as}-\mathrm{cast}}=1$ lies horizontally, the line for $\varepsilon_{\text {fail }} / \varepsilon_{\text {fail-as-cast }}=1$ lies vertically and exceptional materials will lie in the quadrant at upper right which may be labelled the region of "High strength-High ductility". This approach represents an interesting development which is discussed in other reports [83-85].

\section{Summary and conclusions}

1. Tests were conducted to determine the characteristics of the flow properties, and especially the values of the yield stress and ductility, in oxygen-free copper of $>99.95 \%$ purity processed by ECAP at RT for up to 24 passes and then pulled to failure at RT using strain rates from $10^{-4}$ to $10^{-2} \mathrm{~s}^{-1}$.

2. The results show that the microstrain, the dislocation density, the Vickers microhardness and the values of the yield stresses all increase with strain at the lower numbers of ECAP passes but decrease at the highest imposed strains between 16 and 24 passes. There was also a minor increase in the crystallite size between 16 and 24 passes. These results are consistent with the occurrence of dynamic recovery at the highest strain.

3. Tensile testing at RT is important because earlier published data gave conflicting results for the measured elongations to failure after high imposed strains. Taking an imposed strain of about 18 , the present results gave an elongation to failure of $52 \%$ when testing at a strain rate of $10^{-3} \mathrm{~s}^{-1}$ which is very similar to an earlier report using $\mathrm{Cu}$ of much higher purity. This result confirms the potential for achieving good ductility by processing samples by ECAP to high total strains. 


\section{Acknowledgements}

This work was supported by the European Research Council under ERC Grant Agreement No. 267464-SPDMETALS and by the College of Technological Studies under the Public Authority for Applied Education and Training in Kuwait.

\section{Data Availability}

The raw/processed data required to reproduce these findings cannot be shared at this time as the data also forms part of an ongoing study. 


\section{References}

[1] E.O. Hall, The deformation and ageing of mild steel: III. Discussion of results, Proc. Phys. Soc. London B 64 (1951) 747-753.

[2] N.J. Petch, The cleavage strength of polycrystals, J. Iron Steel Inst. 174 (1953) 25-28.

[3] N. Balasubramanian, T.G. Langdon, The strength-grain size relationship in ultrafinegrained metals, Metall. Mater. Trans. A 47A (2016) 5827-5838.

[4] Z.C. Cordero, B.E. Knight, C.A. Schuh, Six decades of the Hall-Petch effect - a survey of grain size strengthening studies on pure metals, Intl Mater. Reviews 61 (2016) 496512.

[5] T.G. Langdon, The mechanical properties of superplastic materials, Metall. Trans. A 13A (1982) 689-701

[6] A.J. Barnes, Superplastic forming 40 years and still growing, J. Mater. Eng. Perform. 16 (2007) 440-454.

[7] R.Z. Valiev, O.A. Kaibyshev, R.I. Kuznetsov, R.Sh. Musalimov, N.K. Tsenev, Lowtemperature superplasticity of metallic materials, Dokl. Akad. Nauk SSSR 301 (1988) 864-866.

[8] R.Z. Valiev, R.K. Islamgaliev, I.V. Alexandrov, Bulk nanostructured materials from severe plastic deformation, Prog. Mater. Sci. 45 (2000) 103-189.

[9] C.C. Koch, T.G. Langdon, E.J. Lavernia, Bulk nanostructured materials, Metall. Mater. Trans. A 48A (2017) 5181-5199.

[10] R.Z. Valiev, Y. Estrin, Z. Horita, T.G. Langdon, M.J. Zehetbauer, Y.T. Zhu, Producing bulk ultrafine-grained materials by severe plastic deformation, JOM 58(4) (2006) 33-39.

[11] Y. Zhu, R.Z. Valiev, T.G. Langdon, N. Tsuji, K. Lu, Processing of nanostructured metals and alloys via plastic deformation, MRS Bull. 35 (2010) 977-981.

[12] T.G. Langdon, Twenty-five years of ultrafine-grained materials: Achieving exceptional properties through grain refinement, Acta Mater. 61 (2013) 7035-7059.

[13] R.Z. Valiev, T.G. Langdon, Principles of equal-channel angular pressing as a processing tool for grain refinement, Prog. Mater. Sci. 51 (2006) 881-981.

[14] A.P. Zhilyaev, T.G. Langdon, Using high-pressure torsion for metal processing: Fundamentals and applications, Prog. Mater. Sci. 53 (2008) 893-979.

[15] A.P. Zhilyaev, B.K. Kim, G.V. Nurislamova, M.D. Baró, J.A. Szpunar, T.G. Langdon, Orientation imaging microscopy of ultrafine-grained nickel, Scripta Mater. 46 (2002) 575-580.

[16] A.P. Zhilyaev, G.V. Nurislamova, B.K. Kim, M.D. Baró, J.A. Szpunar, T.G. Langdon, 
Experimental parameters influencing grain refinement and microstructural evolution during high-pressure torsion, Acta Mater. 51 (2003) 753-765.

[17] J. Wongsa-Ngam, M. Kawasaki, T.G. Langdon, A comparison of microstructures and mechanical properties in a $\mathrm{Cu}-\mathrm{Zr}$ alloy processed using different SPD techniques, J. Mater. Sci. 48 (2013) 4653-4660.

[18] R.Z. Valiev, I.V. Alexandrov, Y.T. Zhu, T.C. Lowe, Paradox of strength and ductility in metals processed by severe plastic deformation. J. Mater. Res. 17 (2002) 5-8.

[19] R. Valiev, Materials science - Nanomaterial advantage, Nature 419 (2002) 887-889.

[20] R. Valiev, Nanostructuring of metals by severe plastic deformation for advanced properties, Nature Mater. 3 (2004) 511-516.

[21] D. Jia, Y.M. Yang, K.T. Ramesh, E. Ma, Y.T. Zhu, R.Z. Valiev, Deformation behavior and plastic instabilities of ultrafine-grained titanium, Appl. Phys. Lett. 79 (2001) 611613.

[22] Y.M. Yang, E. Ma. Strain hardening, strain rate sensitivity, and ductility of nanostructured metals, Mater. Sci. Eng. A 375-377 (2004) 46-52.

[23] C.C. Koch, D.G. Morris, K. Lu, A. Inoue, Ductility of nanostructured materials, MRS Bull. 24(2) (1999) 54-58.

[24] Y.M. Yang, E. Ma, Three strategies to achieve uniform tensile deformation in a nanostructured metal, Acta Mater. 52 (2004) 1699-1709.

[25] Z. Horita, K. Ohashi, T. Fujita, K. Kaneko, T.G. Langdon, Achieving high strength and high ductility in precipitation-hardened alloys, Adv. Mater. 17 (2005) 1599-1602.

[26] E. Ma, Eight routes to improve the tensile ductility of bulk nanostructured metals and alloys, JOM 58(4) (2006) 49-53.

[27] Y.H. Zhao, X.Z. Liao, S. Cheng, E. Ma, Y.T. Zhu, Simultaneously increasing the ductility and strength of nanostructured alloys, Adv. Mater. 18 (2006) 2280-2283.

[28] Y.H. Zhao, J.E. Bingert, X.Z. Liao, B.Z. Cui, K. Han, A.V. Sergueeva, A.K. Mukherjee, R.Z. Valiev, T.G. Langdon, Y.T.T. Zhu, Simultaneously increasing the ductility and strength of ultra-fine-grained pure copper, Adv. Mater. 18 (2006) 2949-2953.

[29] Y.H. Zhao, T. Topping, J.F. Bingert, J.J. Thornton, A.M. Dangelewicz, Y. Li, W. Liu, Y.T. Zhu, Y. Zhou, E.J. Lavernia, High tensile ductility and strength in bulk nanostructured nickel, Adv. Mater. 20 (2008) 3028-3033.

[30] Y.H. Zhao, J.F. Bingert, Y.T. Zhu, X.Z. Liao, R.Z. Valiev, Z. Horita, T.G. Langdon, Y.T. Zhou, E.J. Lavernia, Tougher ultrafine grain $\mathrm{Cu}$ via high-angle grain boundaries and low dislocation density, Appl. Phys. Lett. 92 (2008) 081903.

[31] Y. Zhao, Y. Zhu, E.J. Lavernia, Strategies for improving tensile ductility of bulk 
nanostructured materials, Adv. Eng. Mater. 12 (2010) 769-778.

[32] R.Z. Valiev, A.V. Sergueeva, A.K. Mukherjee, The effect of annealing on tensile deformation behavior of nanostructured SPD titanium, Scripta Mater. 49 (2003) 669-674.

[33] O. Andreau, J. Gubicza, N.X. Zhang, Y. Huang, P. Jenei, T.G. Langdon, Effect of shortterm annealing on the microstructures and flow properties of an Al-1\% Mg alloy processed by high-pressure torsion, Mater. Sci. Eng. A 615 (2014) 231-239.

[34] N. Maury, N.X. Zhang, Y. Huang, A.P. Zhilyaev, T.G. Langdon, A critical examination of pure tantalum processed by high-pressure torsion, Mater. Sci. Eng. A 638 (2015) 174182.

[35] I. Semenova, G. Salimgareeva, G. Da Costa, W. Lefebvre, R. Valiev, Enhanced strength and ductility of ultrafine-grained Ti processed by severe plastic deformation, Adv. Eng. Mater. 12 (2010) 803-807.

[36] A.V. Polyakov, I.P. Semenova, R.Z. Valiev, Y. Huang, T.G. Langdon, Influence of annealing on ductility of ultrafine-grained titanium processed by equal-channel angular pressing-Conform and drawing, MRS Commun. 3 (2013) 249-253.

[37] T. Mungole, P. Kumar, M. Kawasaki, T.G. Langdon, A critical examination of the paradox of strength and ductility in ultrafine-grained metals, J. Mater. Res. 29 (2014) 2534-2546.

[38] F. Dalla Torre, R. Lapovok, J. Sandlin, P.F. Thomson, C.H.J. Davies, E.V. Pereloma, Microstructures and properties of copper processed by equal channel angular extrusion for 1-16 passes, Acta Mater. 52 (2004) 4819-4832.

[39] M. Furukawa, Y. Iwahashi, Z. Horita, M. Nemoto, T.G. Langdon, The shearing characteristics associated with equal-channel angular pressing, Mater. Sci. Eng. A 257 (1998) 328-332.

[40] Y. Iwahashi, J. Wang, Z. Horita, M. Nemoto, T.G. Langdon, Principle of equal-channel angular pressing for the processing of ultra-fine grained materials, Scripta Mater. 35 (1996) 143-146.

[41] L. Lutterotti, Total pattern fitting for the combined size-strain-stress-texture determinations in thin film diffraction, Nucl. Instrum. Methods Phys. Res. Sect. B 268 (2010) 334-340.

[42] H.M. Rietveld, A profile refinement method for nuclear and magnetic structures, J. Appl. Crystallogr. 2 (1969) 65-71.

[43] G. Williamson, R. Smallman, III. Dislocation densities in some annealed and coldworked metals from measurements on the X-ray debye-scherrer spectrum, Philos Mag 1 (1956) 34-46.

[44] Smallman R, Westmacott K. Stacking faults in face-centred cubic metals and alloys. Philos Mag 2 (1957) 669-683. 
[45] Y.T. Zhu, J.Y. Huang, J. Gubicza, T. Ungár, Y.M. Yang. E. Ma, R.Z. Valiev, Nanostructures in Ti processed by severe plastic deformation, J. Mater. Res. 18 (2003) 1908-1917.

[46] Y.H. Zhao Y.T. Zhu, X.Z. Liao, Z. Horita, T.G. Langdon, Influence of stacking fault energy on the minimum grain size achieved in severe plastic deformation, Mater. Sci. Eng. A 463 (2007) 22-26.

[47] K. Máthis, J. Gubicza, N.H. Nam, Microstructure and mechanical behavior of AZ91 Mg alloy processed by equal channel angular pressing, J. Alloys Compd. 394 (2005) 194199.

[48] E. Bagherpour, F. Qods, R. Ebrahimi, H. Miyamoto, Nanostructured pure copper fabricated by simple shear extrusion (SSE): a correlation between microstructure and tensile properties, Mater. Sci. Eng. A 679 (2017) 465-475.

[49] E.W. Hart, Theory of the tensile test, Acta Metall. 15 (1967) 351-355.

[50] S. Yip, Nanocrystals: the strongest size, Nature 391 (1998) 532-533.

[51] J. Schiøtz, K.W. Jacobsen, A maximum in the strength of nanocrystalline copper, Science 301 (2003) 1357-1359.

[52] A. Loucif, R.B. Figueiredo, T. Baudin, F. Brisset, R. Chemam, T.G. Langdon, Ultrafine grains and the Hall-Petch relationship in an Al-Mg-Si alloy processed by high-pressure torsion, Mater. Sci. Eng. A 532 (2012) 139-145.

[53] J. Schiøtz, F.D. Di Tolla, K.W. Jacobsen, Softening of nanocrystalline metals at very small grain sizes, Nature 391 (1998) 561-563.

[54] J. Schiøtz, T. Vegge, F.D. Di Tolla, K.W. Jacobsen, Atomic-scale simulations of the mechanical deformation of nanocrystalline metals, Phys. Rev. B 60 (1999) 1197111983.

[55] H. Van Swygenhoven, Grain boundaries and dislocations, Science 296 (2002) 66-67.

[56] N.Q. Chinh, G. Horváth, Z. Horita, T.G. Langdon, A new constitutive relationship for the homogeneous deformation of metals over a wide range of strain, Acta Mater. 52 (2004) 3555-3563.

[57] N. Lugo, N. Llorca, J.J. Suñol, J.M. Cabrera, Thermal stability of ultrafine grains size of pure copper obtained by equal-channel angular pressing, J. Mater. Sci. 45 (2010) 22642273.

[58] K. Edalati, K. Imamura, T. Kiss, Z. Horita, Equal-channel angular pressing and highpressure torsion of pure copper: evolution of electrical conductivity and hardness with strain, Mater. Trans. 53 (2012) 123-127.

[59] M. Ebrahimi, C. Gode, Severely deformed copper by equal channel angular pressing, 
Prog. Nat. Sci.: Mater. Int. 27 (2017) 244-250.

[60] H. Jiang, Y.T. Zhu, D.P. Butt, I.V. Alexandrov, T.C. Lowe, Microstructural evolution, microhardness and thermal stability of HPT-processed Cu, Mater. Sci. Eng. A 290 (2000) $128-138$.

[61] K. Edalati, T. Fujioka, Z. Horita, Microstructure and mechanical properties of pure $\mathrm{Cu}$ processed by high-pressure torsion, Mater. Sci. Eng. A 497 (2008) 168-173.

[62] K. Edalati, Y. Ito, K. Suehiro, Z. Horita, Softening of high purity aluminum and copper processed by high pressure torsion, Intl J. Mater. Res. 100 (2009) 1668-1673.

[63] K. Edalati, Z. Horita, Universal plot for hardness variation in pure metals processed by high-pressure torsion, Mater. Trans. 51 (2010) 1051-1054.

[64] K. Edalati, Z. Horita, Significance of homologous temperature in softening behavior and grain size of pure metals processed by high-pressure torsion, Mater. Sci. Eng. A 528 (2011) 7514-7523.

[65] X.H. An, Q.Y. Lin, S.D. Wu, Z.F. Zhang, R.B. Figueiredo, N. Gao, T.G. Langdon, Significance of stacking fault energy on microstructural evolution in $\mathrm{Cu}$ and $\mathrm{Cu}-\mathrm{Al}$ alloys processed by high-pressure torsion, Philos. Mag. 91 (2011) 3307-3326.

[66] J.T. Wang, Y. Zhang, J.Q. Liu, Continuous recrystallization phenomenon in high purity copper during equal channel angular pressing up to high strain at room temperature, Mater. Sci. Forum 584-586 (2008) 929-937.

[67] N. Hansen, Hall-Petch relation and boundary strengthening, Scripta Mater. 51 (2004) 801-806.

[68] M. Reihanian, R. Ebrahimi, N. Tsuji, M.M. Moshksar, Analysis of the mechanical properties and deformation behavior of nanostructured commercially pure Al processed by equal channel angular pressing (ECAP), Mater. Sci. Eng. A 473 (2008) 189-194.

[69] I. Sabirov, M.Y. Murashkin, R.Z. Valiev, Nanostructured aluminium alloys produced by severe plastic deformation: New horizons in development, Mater. Sci. Eng. A 560 (2013) $1-24$.

[70] N. Haghdadi, A. Zarei-Hanzaki, D. Abou-Ras, Microstructure and mechanical properties of commercially pure aluminum processed by accumulative back extrusion, Mater. Sci. Eng. A 584 (2013) 73-81.

[71] M.M. Abramova, N.A. Enikeev, R.Z. Valiev, A. Etienne, B. Radiguet, Y. Ivanisenko, X. Sauvage, Grain boundary segregation induced strengthening of an ultrafine-grained austenitic stainless steel, Mater. Lett. 136 (2014) 349-352.

[72] N. Kamikawa, X. Huang, N. Tsuji, N. Hansen, Strengthening mechanisms in nanostructured high-purity aluminium deformed to high strain and annealed, Acta Mater. 57 (2009) 4198-4208. 
[73] U.F. Kocks, H.F. Mecking, Physics and phenomenology of strain hardening: the FCC case, Prog. Mater. Sci. 48 (2003) 171-273.

[74] W. Blum, X.H. Zeng, A simple deformation model of deformation resistance of ultrafinegrained materials explaining Hall-Petch strengthening and enhanced strain rate sensitivity, Acta Mater. 57 (2009) 1966-1974.

[75] K. Zhang, B. Holmedal, T. Mánik, A. Saai, Assessment of advanced Taylor models, the Taylor factor and yield-surface exponent for FCC metals, Intl J. Plast. 114 (2019) 144160.

[76] J. Gubicza, N.Q. Chinh, Z. Horita, T.G. Langdon, Effect of Mg addition on microstructure and mechanical properties of aluminum, Mater. Sci. Eng.. A 387-389 (2004) 55-59.

[77] J. Gubicza, N.Q. Chinh, J.L. Lábár, S. Dobatkin, Z. Hegedűs, T.G. Langdon, Correlation between microstructure and mechanical properties of severely deformed metals, J. Alloys Compd. 483 (2009) 271-274.

[78] E. Schafler, G. Steiner, E. Korznikova, M. Kerber, M.J. Zehetbauer, Lattice defect investigation of ECAP-Cu by means of X-ray line profile analysis, calorimetry and electrical resistometry, Mater. Sci. Eng. A 410-411 (2005) 169-173.

[79] F.H. Dalla Torre, E.V. Pereloma, C.H.J. Davies, Strain hardening behaviour and deformation kinetics of $\mathrm{Cu}$ deformed by equal channel angular extrusion from 1 to 16 passes, Acta Mater. 54 (2006) 1135-1146.

[80] K. Nakashima, Z. Horita, M. Nemoto, T.G. Langdon, Influence of channel angle on the development of ultrafine grains in equal-channel angular pressing, Acta Mater. 46 (1998) 1589-1599.

[81] R.B. Figueiredo, I.J. Beyerlein, A.P. Zhilyaev, T.G. Langdon, Evolution of texture in a magnesium alloy processed by ECAP through dies with different angles, Mater. Sci. Eng. A 527 (2010) 1709-1718.

[82] J.K. Han, K.D. Liss, T.G. Langdon, J.I. Jang, M. Kawasaki, Mechanical properties and structural stability of a bulk nanostructured metastable aluminum-magnesium system, Mater. Sci. Eng. A 796 (2020) 140050.

[83] P. Kumar, M. Kawasaki, T.G. Langdon, Review: Overcoming the paradox of strength and ductility in ultrafine-grained materials at low temperatures, J. Mater. Sci. 51 (2016) $7-18$.

[84] S.H. Bae, K.H. Jung, Y.C. Shin, D.J. Yoon, M. Kawasaki, Development of mechanical properties in a $\mathrm{CaO}$ added AZ31 magnesium alloy processed by equal-channel angular pressing, Mater. Char. 112 (2016) 105-112.

[85] I.A. Ovid'ko, R.Z. Valiev, Y.T. Zhu, Review on superior strength and enhanced ductility of metallic nanomaterials, Prog. Mater. Sci. 94 (2018) 462-540. 


\section{Figure captions:}

Fig. 1 OIM images of oxygen-free copper processed by ECAP for up to 24 passes at room temperature.

Fig. 2 Distributions of proportions of grain boundary misorientation angles for oxygen-free copper processed by ECAP for up to 24 passes at room temperature.

Fig. 3 (a) Crystallite size and microstrain and (b) dislocation density plotted as a function of numbers of ECAP passes.

Fig. 4 Vickers microhardness of oxygen-free $\mathrm{Cu}$ processed by ECAP for up to 24 passes plotted as a function of numbers of passes.

Fig. 5 Curves of engineering stress-engineering strain for oxygen-free copper processed by ECAP at room temperature and tested in tension using strain rates of (a) $1.0 \times 10^{-2} \mathrm{~s}^{-1}$, (b) $1.0 \times 10^{-3} \mathrm{~s}^{-1}$ and (c) $1.0 \times 10^{-4} \mathrm{~s}^{-1}$.

Fig. 6 Flow stress-strain rate curves showing the calculated values of the strain rate sensitivities for oxygen-free $\mathrm{Cu}$ processed by ECAP at room temperature.

Fig. 7 Work hardening rate as a function of true strain for oxygen-free copper processed by ECAP for up to 24 passes.

Fig. 8 Evolution of yield stress as a function of the average grain size for oxygen-free copper processed by ECAP at room temperature.

Fig. 9 Estimated yield stress plotted against number of passes for oxygen-free copper processed by ECAP at room temperature.

Fig. 10 The conventional paradox of strength and ductility diagram: almost all UFG metals lie in the shaded area below the curve where data are shown for $\mathrm{Al}$ and $\mathrm{Cu}$, the numbers against the lines denote the strains imposed in cold rolling and the results plot the yield stress against the elongation to failure; also shown are points for nano Ti processed by HPT for 10 turns [18] and two points for nano $\mathrm{Cu}$ after processing by ECAP to strains of 18.4 [18] and 18.2, respectively. 


\section{Table captions:}

Table 1 Values of yield strength (YS) and total elongation to failure (EL) for specimens pulled in tension through various numbers of ECAP passes at strain rates from $10^{-2}$ to $10^{-4}$ $\mathrm{s}^{-1}$.

Table 2 Values of UTS and uniform elongation (UEL) for specimens pulled in tension through various numbers of ECAP passes at strain rates from $10^{-2}$ to $10^{-4} \mathrm{~s}^{-1}$.

Table 3 Experimental data from three different investigations of pure $\mathrm{Cu}$. 
(a)

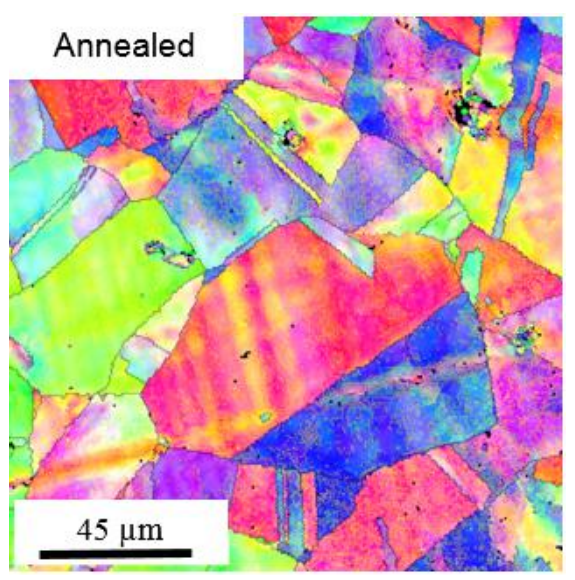

(c)

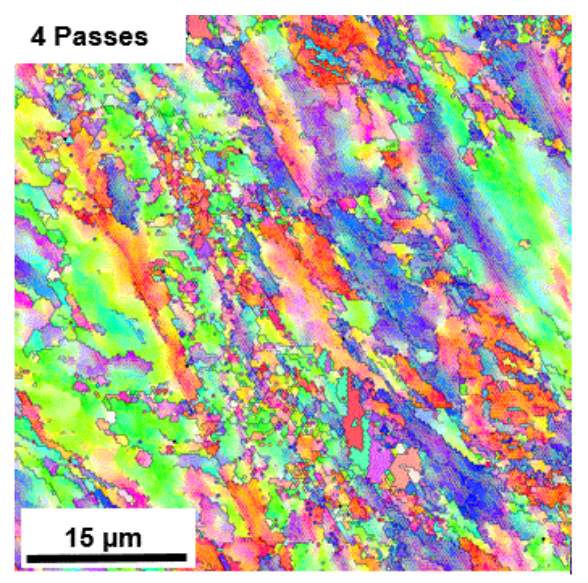

(e) 16 Passes ofy

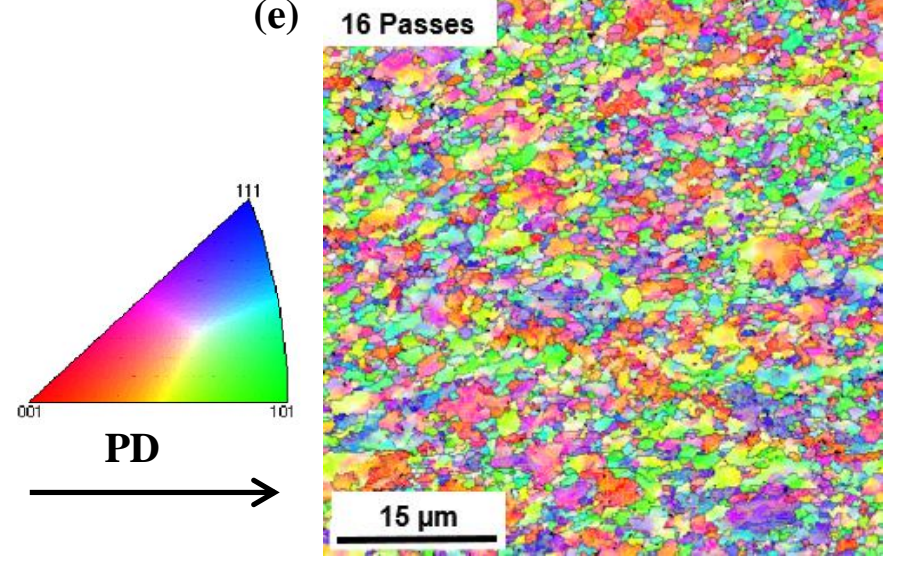

(b)

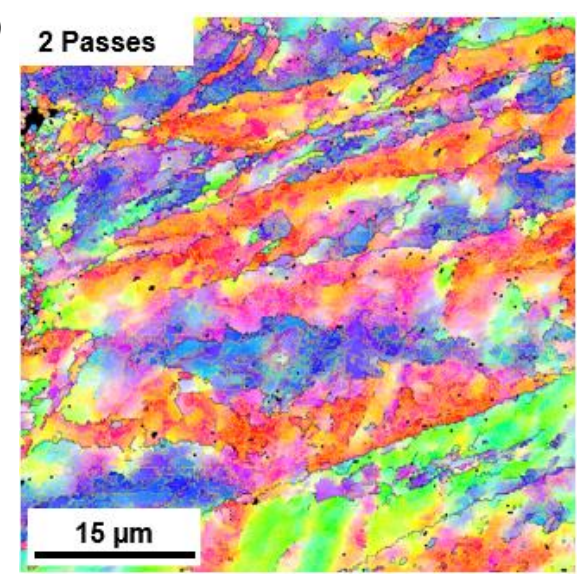

(d)

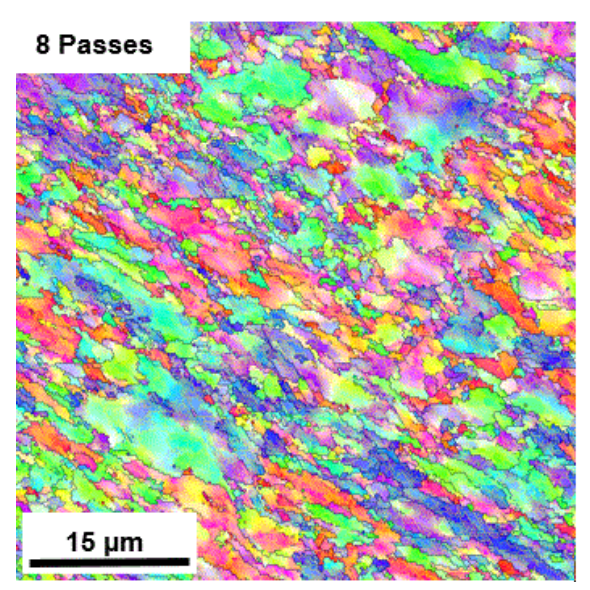

(f)

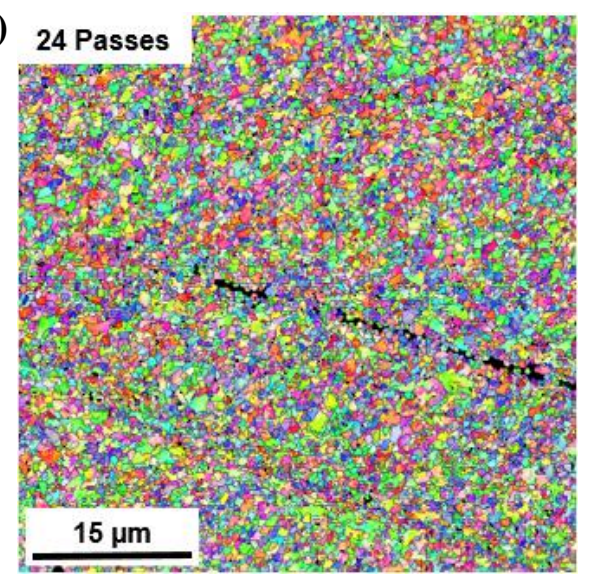

Fig. 1 OIM images of oxygen-free copper processed by ECAP for up to 24 passes at room temperature. 
(a)

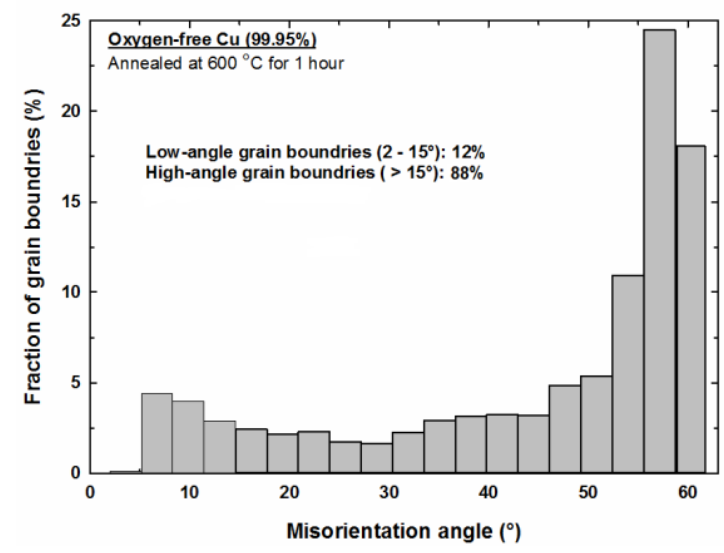

(c)

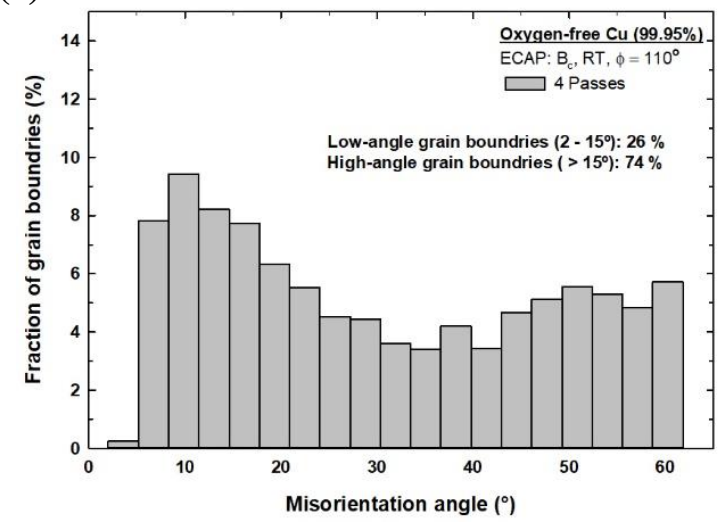

(e)

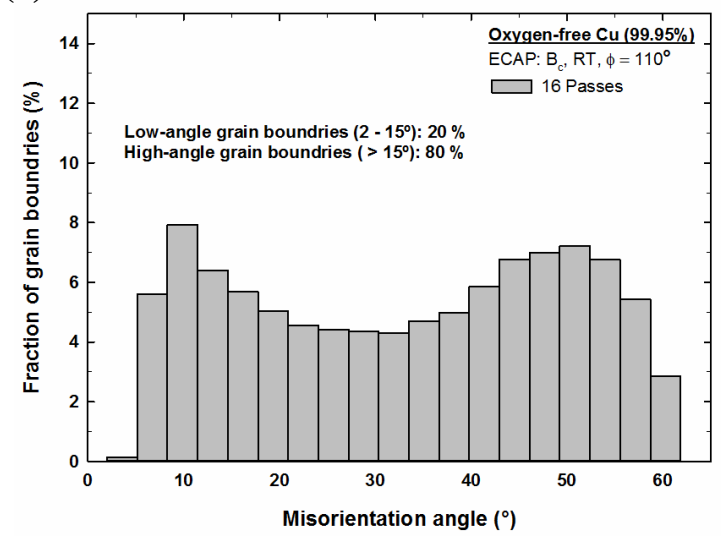

(b)

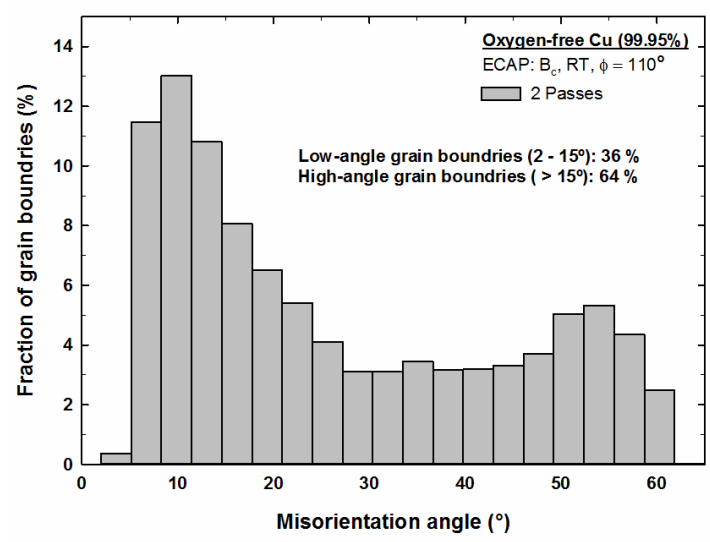

(d)

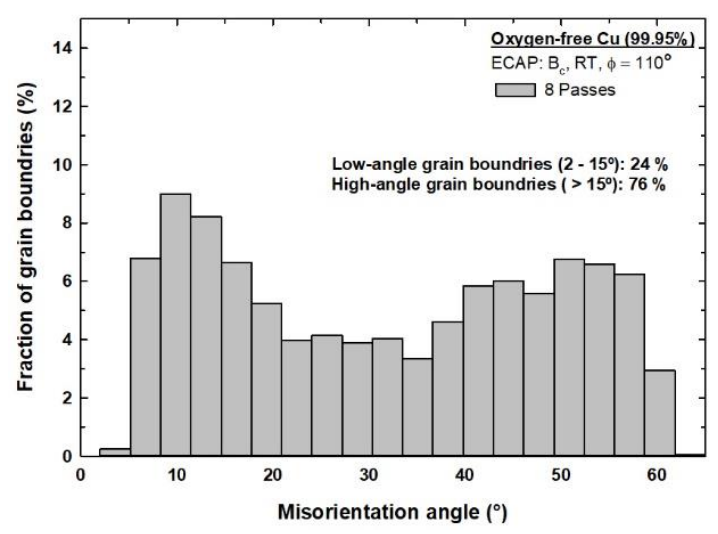

(f)

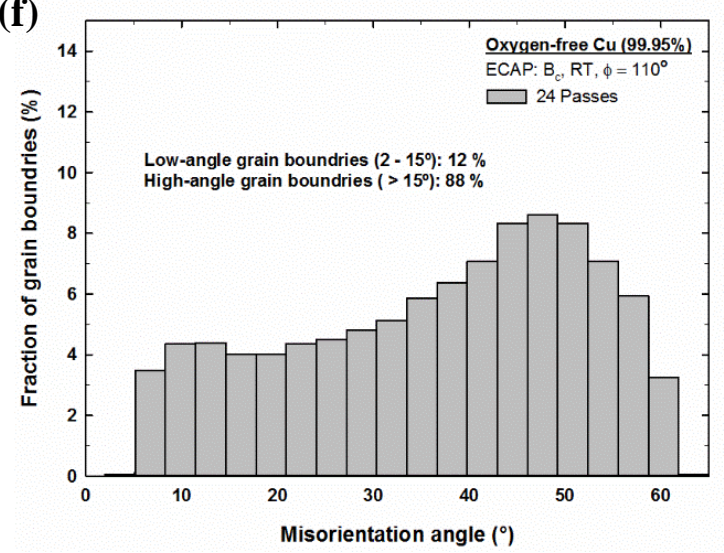

Fig. 2 Distribution of proportion of misorientation angles of the grain boundaries of oxygen-free copper processed by ECAP for up to 24 passes at room temperature. 
(a)

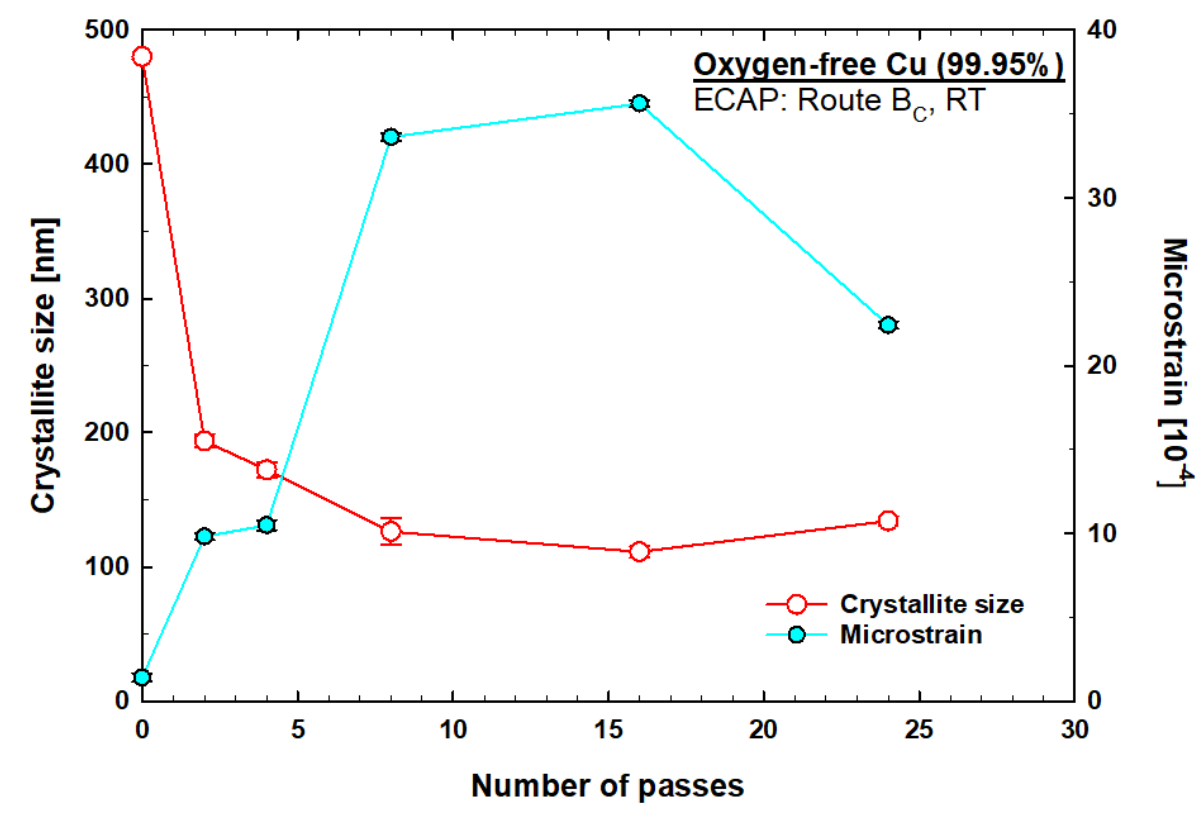

(b)

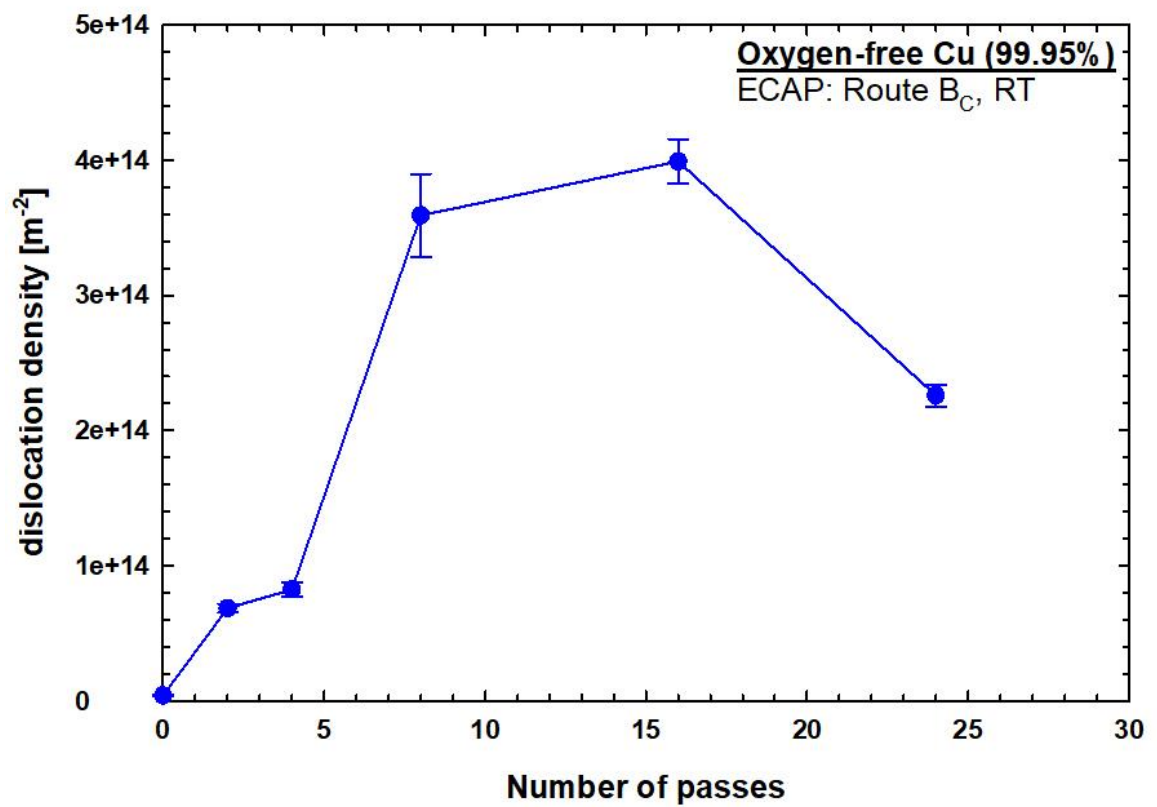

Fig. 3 (a) Crystallite size and microstrain and (b) dislocation density plotted as a function of numbers of ECAP passes. 


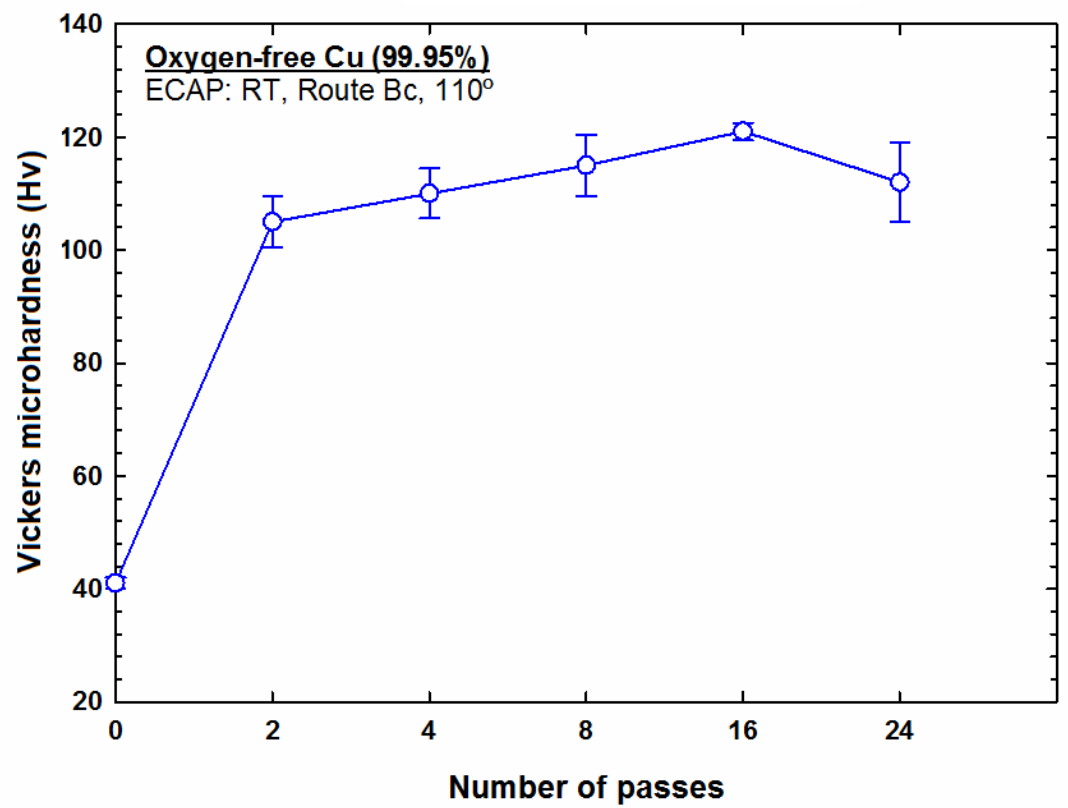

Fig. 4 Vickers microhardness of oxygen-free $\mathrm{Cu}$ processed by ECAP for up to 24 passes plotted as a function of numbers of passes. 
(a)

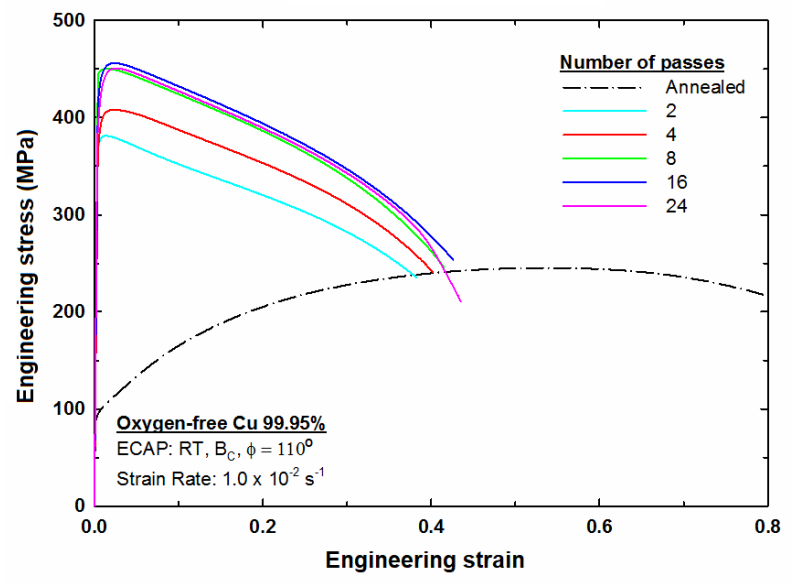

(b)

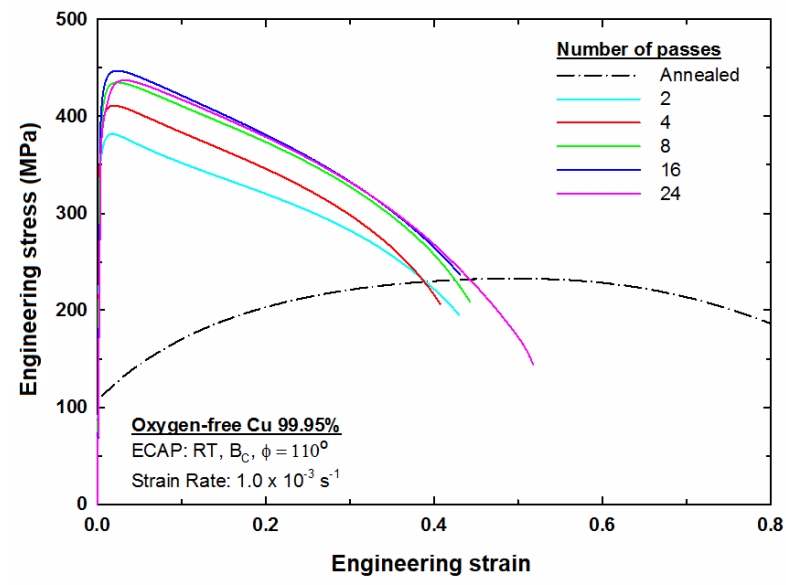

(c)

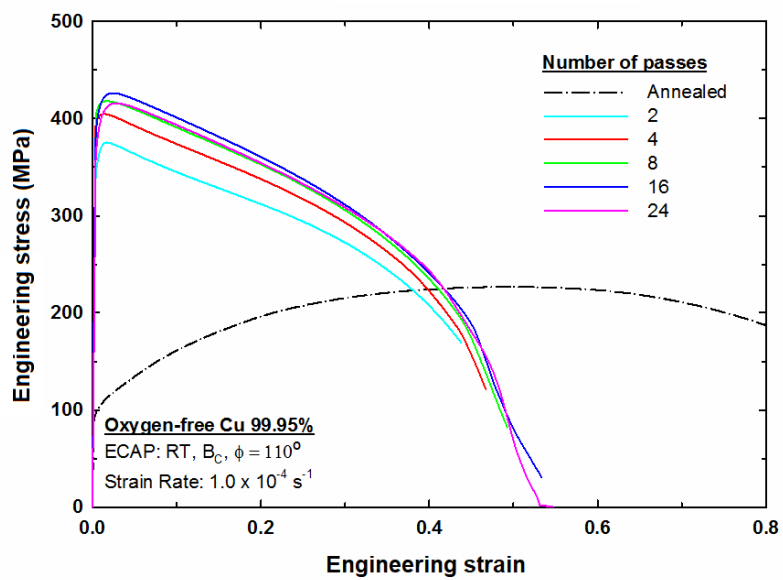


Fig. 5 Engineering stress-engineering strain curves of oxygen-free copper processed by ECAP at room temperature and tested in tension using strain rates of: (a) $1.0 \times 10^{-2} \mathrm{~s}^{-1}$, (b) $1.0 \times 10^{-3} \mathrm{~s}^{-1}$ and (c) $1.0 \times 10^{-4} \mathrm{~s}^{-1}$.

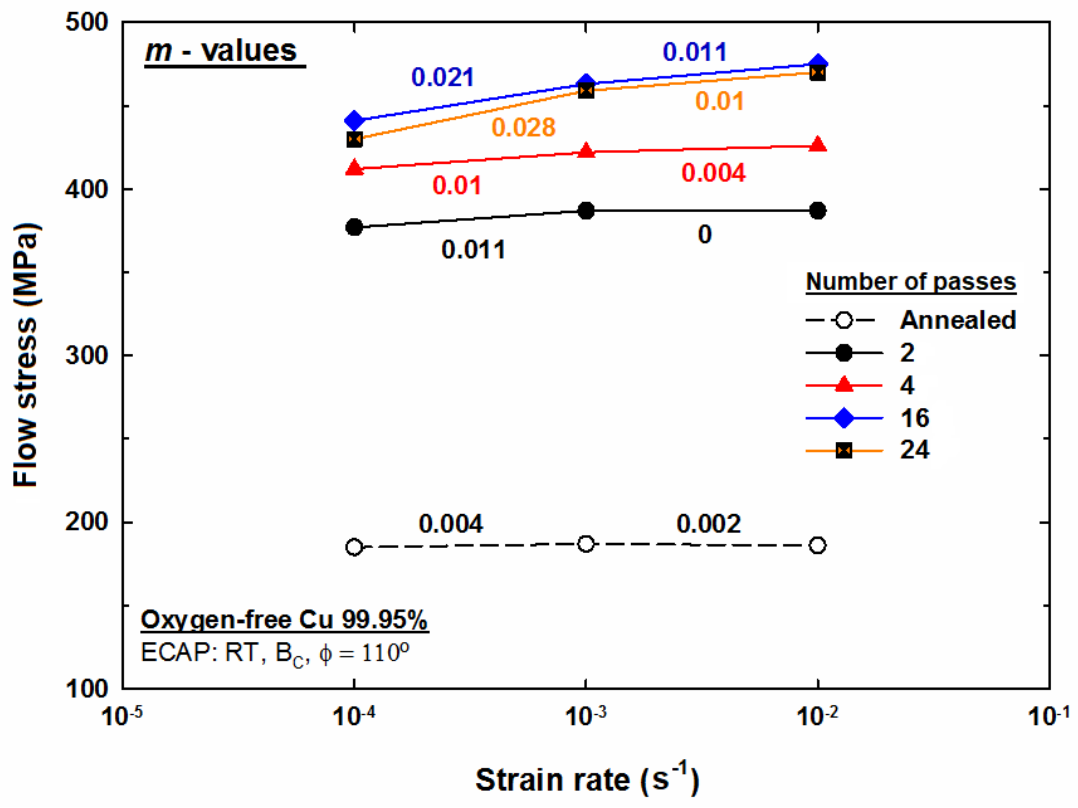

Fig. 6 Flow stress-strain rate curves showing the calculated values of the strain rate sensitivities for oxygen-free $\mathrm{Cu}$ processed by ECAP at room temperature. 


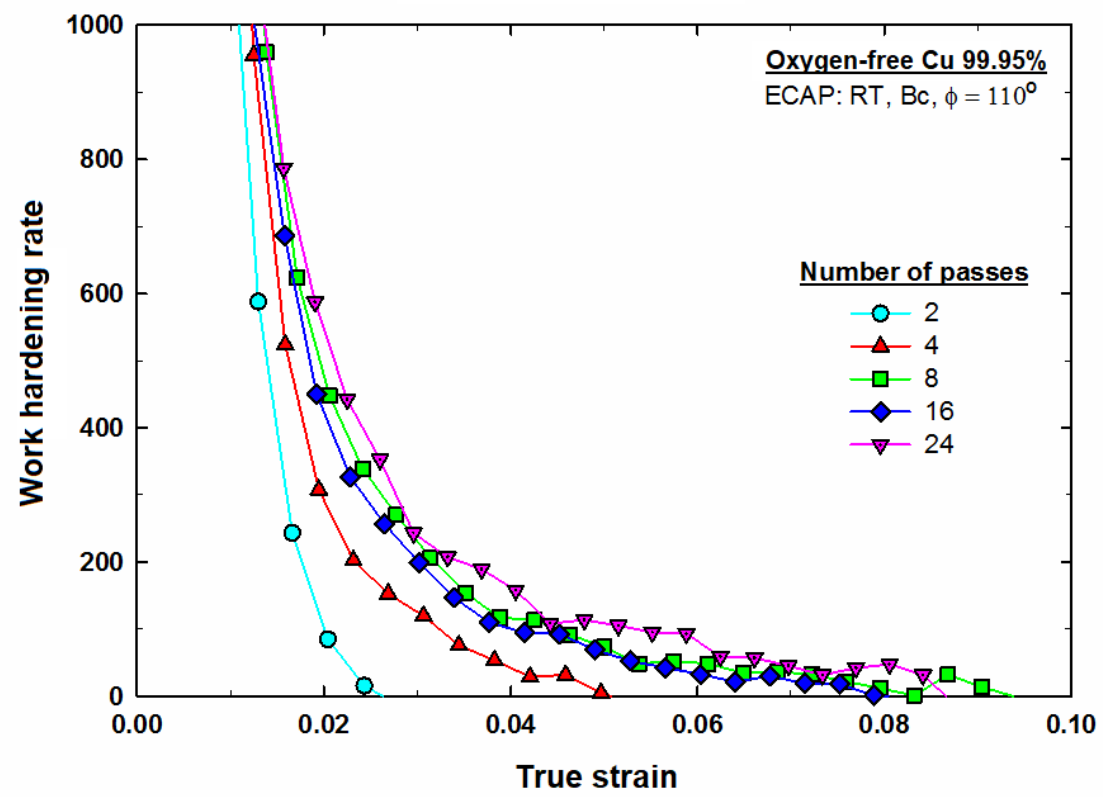

Fig. 7 Work-hardening rate as a function of true strain for oxygen-free copper processed by ECAP by up to 24 passes. 


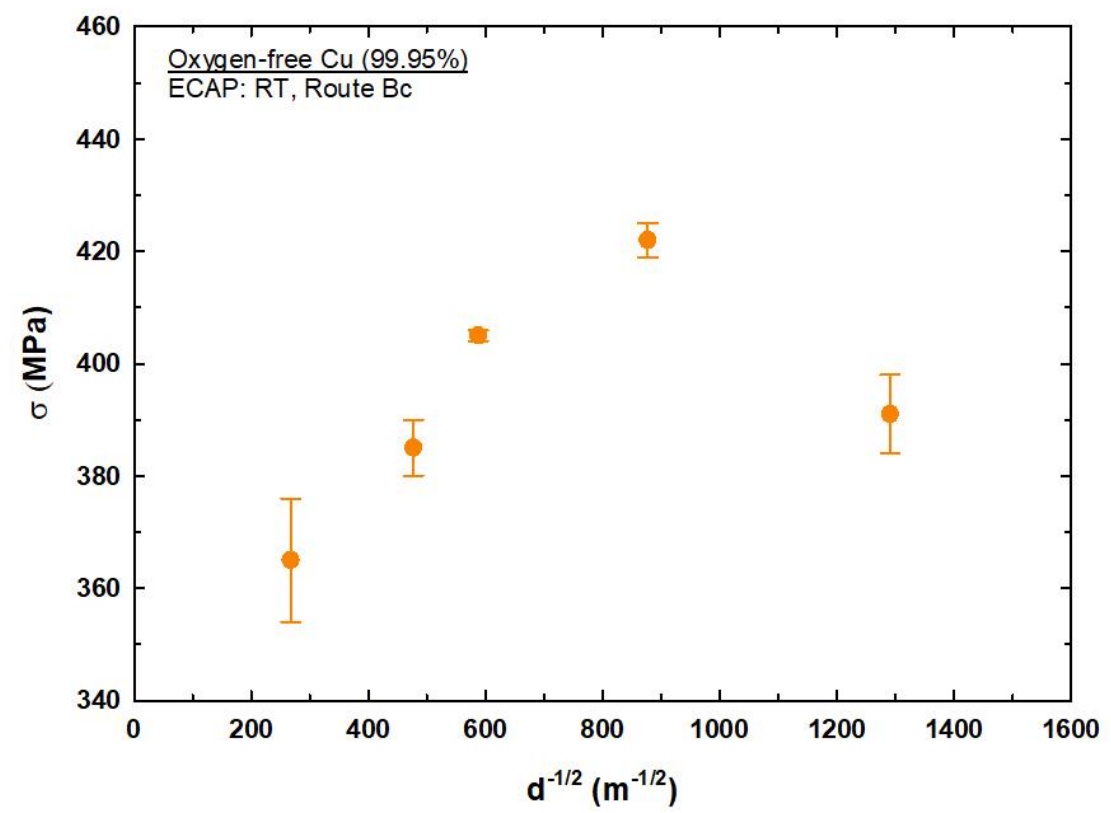

Fig. 8 Evolution of yield stress as a function of the average grain size for oxygen free copper processed by ECAP at room temperature. 


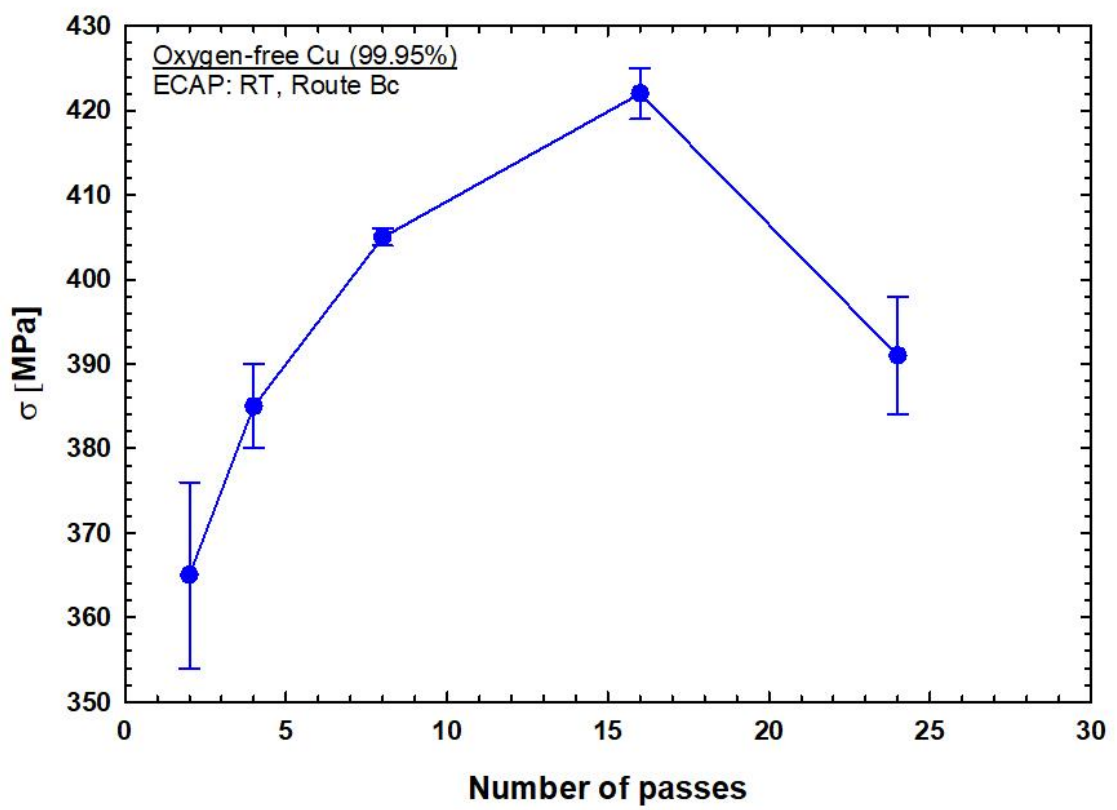

Fig. 9 Estimated yield stress plotted against number of passes for oxygen-free copper processed by ECAP at room temperature. 


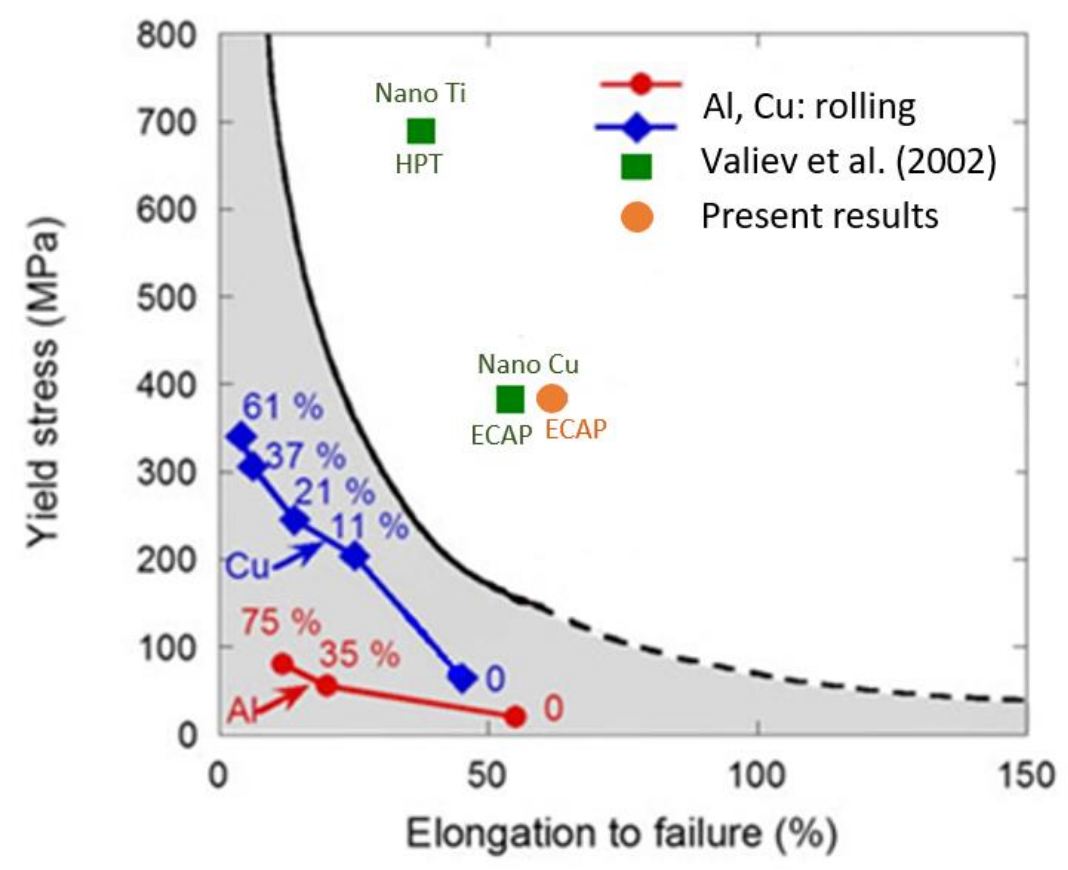

Fig. 10 The conventional paradox of strength and ductility diagram: almost all UFG metals lie in the shaded area below the curve where data are shown for $\mathrm{Al}$ and $\mathrm{Cu}$, the numbers against the lines denote the strains imposed in cold rolling and the results plot the yield stress against the elongation to failure; also shown are points for nano Ti processed by HPT for 10 turns [18] and two points for nano $\mathrm{Cu}$ after processing by ECAP to strains of 18.4 [18] and 18.2, respectively. 


\section{Table 1}

Values of yield strength (YS) and total elongation to failure (EL) for specimens pulled in tension through various numbers of ECAP passes at strain rates from $10^{-2}$ to $10^{-4} \mathrm{~s}^{-1}$.

\begin{tabular}{c|c|c|c|c|c|c}
\hline \multirow{2}{*}{ No. of passes } & \multicolumn{2}{|c|}{$\dot{\varepsilon}=1.0 \times 10^{-2} \mathrm{~s}^{-1}$} & \multicolumn{2}{c|}{$\dot{\varepsilon}=1.0 \times 10^{-3} \mathrm{~s}^{-1}$} & \multicolumn{2}{c}{$\dot{\varepsilon}=1.0 \times 10^{-4} \mathrm{~s}^{-1}$} \\
\cline { 2 - 7 } & $\begin{array}{c}\text { YS (0.2\%) } \\
(\mathrm{MPa})\end{array}$ & $\mathrm{EL}(\%)$ & $\begin{array}{c}\text { YS }(0.2 \%) \\
(\mathrm{MPa})\end{array}$ & $\mathrm{EL}(\%)$ & $\begin{array}{c}\text { YS }(0.2 \%) \\
(\mathrm{MPa})\end{array}$ & $\mathrm{EL}(\%)$ \\
\hline 0 (Annealed) & $90 \pm 5$ & $95 \pm 6$ & $110 \pm 6$ & $100 \pm 4$ & $93 \pm 3$ & $104 \pm 8$ \\
\hline 2 & $371 \pm 4$ & $38 \pm 5$ & $365 \pm 11$ & $43 \pm 6$ & $349 \pm 6$ & $44 \pm 4$ \\
\hline 4 & $386 \pm 2$ & $40 \pm 3$ & $386 \pm 5$ & $41 \pm 3$ & $398 \pm 5$ & $47 \pm 3$ \\
\hline 16 & $447 \pm 3$ & $41 \pm 2$ & $405 \pm 1$ & $44 \pm 2$ & $408 \pm 4$ & $49 \pm 5$ \\
\hline 24 & $430 \pm 1$ & $42 \pm 4$ & $422 \pm 3$ & $43 \pm 5$ & $412 \pm 5$ & $53 \pm 3$ \\
\hline
\end{tabular}




\section{Table 2}

Values of UTS and uniform elongation (UEL) for specimens pulled in tension through various numbers of ECAP passes at strain rates from $10^{-2}$ to $10^{-4} \mathrm{~s}^{-1}$.

\begin{tabular}{c|c|c|c|c|c|c}
\hline \multirow{2}{*}{ No. of passes } & \multicolumn{2}{|c|}{$\dot{\varepsilon}=1.0 \times 10^{-2} \mathrm{~s}^{-1}$} & \multicolumn{2}{c|}{$\dot{\varepsilon}=1.0 \times 10^{-3} \mathrm{~s}^{-1}$} & \multicolumn{2}{c}{$\dot{\varepsilon}=1.0 \times 10^{-4} \mathrm{~s}^{-1}$} \\
\cline { 2 - 7 } & UTS (MPa) & UEL (\%) & UTS (MPa) & UEL (\%) & UTS (MPa) & UEL (\%) \\
\hline 2 & $381 \pm 5$ & $1.4 \pm 0.4$ & $382 \pm 7$ & $1.7 \pm 0.7$ & $375 \pm 5$ & $1.7 \pm 0.7$ \\
\hline 4 & $408 \pm 5$ & $2.3 \pm 0.2$ & $411 \pm 5$ & $1.9 \pm 0.3$ & $404 \pm 2$ & $1.4 \pm 0.3$ \\
\hline 8 & $450 \pm 2$ & $1.5 \pm 0.6$ & $434 \pm 2$ & $2.2 \pm 0.3$ & $418 \pm 3$ & $1.7 \pm 0.2$ \\
\hline 16 & $456 \pm 4$ & $2.4 \pm 0.5$ & $447 \pm 5$ & $2.4 \pm 0.4$ & $426 \pm 1$ & $2.4 \pm 0.3$ \\
\hline
\end{tabular}




\section{Table 3}

Experimental data from three different investigations of pure $\mathrm{Cu}$.

\begin{tabular}{|c|c|c|c|c|c|c|c|c|c|c|c|}
\hline \multirow[b]{2}{*}{ Purity } & \multicolumn{4}{|c|}{ ECAP conditions } & \multirow[b]{2}{*}{$d(\mathrm{~nm})$} & \multicolumn{5}{|c|}{ Tensile testing conditions } & \multirow[b]{2}{*}{ Reference } \\
\hline & Temp. & $\Phi$ & $N$ & $\varepsilon$ & & $\dot{\varepsilon}\left(\mathrm{s}^{-1}\right)$ & Temp. & YS (MPa) & Elongation & $m$ & \\
\hline $99.996 \%$ & $\mathrm{RT}$ & $90^{\circ}$ & 16 & 18.4 & $\sim 400$ & $10^{-3}$ & $\mathrm{RT}$ & $\sim 400$ & $51 \%$ & 0.14 & Valiev et al. [18] \\
\hline$>99.95 \%$ & RT & $90^{\circ}$ & 16 & 18.4 & $\sim 180$ & $1.6 \times 10^{-3}$ & RT & $\sim 345$ & $10 \%$ & $0.022 \dagger$ & $\begin{array}{c}\text { Dalla Torre et al. } \\
\qquad[38]\end{array}$ \\
\hline$>99.95 \%$ & RT & $110^{\circ}$ & 24 & 18.2 & $\sim 600$ & $10^{-3}$ & RT & $\sim 391$ & $52 \%$ & 0.028 & This investigation \\
\hline
\end{tabular}

$\uparrow$ Value of $m$ determined for this material using strain rate jump tests in compression instead of testing in tension [79]. 